\title{
On the effect of curing time and environmental exposure on impregnated Carbon Fabric Reinforced Cementitious Matrix (CFRCM) composite with design considerations
}

\author{
A. Nobili ${ }^{\mathrm{a}, *}$, C. Signorini ${ }^{\mathrm{b}}$ \\ ${ }^{a}$ Dipartimento di Ingegneria Enzo Ferrari, via Vignolese 905, 41125 Modena, Italy \\ ${ }^{b}$ Dipartimento di Scienze e Metodi dell'Ingegneria, via Amendola 2, 42122 Reggio Emilia, \\ Italy
}

\begin{abstract}
This paper investigates the effect of curing time and aggressive environmental exposure on the mechanical performance of impregnated Carbon Fabric Reinforced Cementitious Matrix (CFRCM) composite. Following the recently published IIC-ES AC434 guidelines, saltwater, distilled water, alkali and acid resistance are investigated together with freeze-thaw cycles. Mechanical characterization is based on tensile uni-axial tests under deformation control of rectangular-base prismatic specimens. 28- and 60-day curing times are considered for the control environment as well as for saltwater and alkali resistance. Deformation is monitored via digital acquisition. Besides uni-axial tests, experimental results comprise optical and scanning electron microscopy, crack pattern analysis and failure mechanism assessment. Focus is set on the determination of the design limits for the composite system at failure for the tested environments and curing times. In particular, a comparison is drawn with established design criteria already coded for FRP systems, which introduce the concept of safety (or partial) factors. Environmental conversion factors are also defined and calculated on a statistical basis in a twofold manner, as a mean to determine the design strain and strength limits of exposed specimens from the control (unex-
\end{abstract}

* Corresponding author

Preprint submitted to Elsevier

November 16, 2016 
posed) data. It is found that they provide a convenient method for assessing the composite vulnerability to the aggressive environments at different curing times.

Keywords: Durability, Fabric reinforced Cementitious Material, Impregnated Carbon Fabric, Design criteria

\section{Introduction}

Fabric Reinforced Cementitious Matrix (FRCM) composite stands out as a new class of material available to the structural engineer for designing reliable and cost-effective strengthening and retrofitting systems for concrete and masonry structures. The use of fabric to reinforce structural components has been a key driving technology in the last 20 years, for it reconciles ease of manufacturing with excellent anchorage at little cost [26]. This appealing concept has been declined into several forms within the construction industry, ranging from textile reinforced concrete (TRC) or mortar (TRM), to fiber-reinforced polymers (FRP), from ferrocement to FRCM. Although the common ground for such acronyms is sometimes slippery, we may still group these technology according to the nature of the matrix which holds the reinforcement grids bonded together and, possibly, to the structural element (in the so-called strengthening system) and according to the nature of the fabric deployed. According to the former classification, we may distinguish ductile organic matrices, which are most often constituted by polymeric materials and thereby falls in the FRP group, from brittle inorganic ones, composed of cement or mortar-based materials, respectively under the heading of TRC or TRM (although the wording fabric-cement composite, FCC, is also in common use). Similarly, a wide variety of materials may be adopted for the reinforcing fabric which may be grouped under several criteria: conventional materials, such as steel or glass, high-modulus materials, such as aramidic fibers (Kevlar), carbon fibers or synthetic polymers (Zylon, better known as polyphenylene-benzobisoxazole or PBO), low-modulus (polypropylene) or even natural fibers (straw, cellulose, hemp). All these tech- 
nologies may be labeled together under the common heading of continuous fiber reinforcing material (CFRM), as opposed to randomly distributed discontinuous fiber reinforced materials, such as fiber reinforced concrete (FRC) [6, 22].

While FRP possesses a substantial history of successful applications to its credit [33], growing interest has been recently attracted by cement-based composites, in light of some important advantages [29, 7]. Indeed, unlike FRP, cement-based composites are noncombustible nor they contribute to fuel the fire, they are fully recyclable and easily incorporate recycled materials, they possess high compatibility with the usual construction substrates and reversibility of installation and for this they gain wider acceptance, with special regard to cultural heritage seismic upgrading. Besides, they generally retain high levels of water vapor permeability (breathability), especially when considering lowcement content or lime-based mortars with no polymeric addition, and remarkable mechanical properties. In fact, apart from steel, cement-based composites possess the best strength-to-weight ratio of any building material [25].

Currently, lack of adequate building code provisions greatly hinders large scale project application of FRCM strengthening, which manly rely on ad-hoc experimental validation $[12,30,32,13,28]$. Recently, some important progress has been made by the International Code Council Evaluation Services (ICC-ES) [17] and by the International union of laboratories and experts in construction materials, systems and structures (RILEM) [31]. In particular, ICC provides guidelines for acceptance and characterization of FRCM materials, a recognition procedure for evaluation reports under the International Building Code [18] and minimum acceptable design criteria.

In this paper, we consider the effect of curing time and aggressive environment exposure on the mechanical performance in uni-axial tensile test of CFRCM coupons according to ICC indications. Indeed, while much work has been devoted to developing a sound knowledge of fabric bonding and pullout mechanisms $[5,11,10]$, limited data are currently available in the literature concerning FRCM durability $[8,16,9,4,27]$. Spotlight is set on assessing the composite design limits according to ICC design criteria for all test environ- 


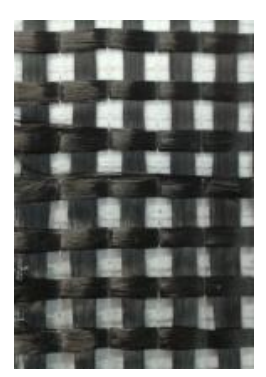

Figure 1: Carbon fabric grid

\begin{tabular}{|l|c|c|}
\hline Characteristic & Unit & Value \\
\hline Mean compression strength after 28 days & $\mathrm{MPa}$ & 6.5 \\
Mean flexural strength after 28 days & $\mathrm{MPa}$ & 3 \\
Support adhesion strength after 28 days & $\mathrm{MPa}$ & 1 \\
Water content & - & $23 \%$ \\
Aggregate maximum size & $\mathrm{mm}$ & 0.7 \\
Longitudinal elastic modulus & $\mathrm{GPa}$ & 11 \\
\hline
\end{tabular}

Table 1: Mortar properties

ments and curing times and on comparing such results with some established design protocol for FRP systems.

\section{Materials and method}

\subsection{Materials}

All specimens considered in this analysis are manufactured according to Annex A of [17] using a commercially available pozzolan-based mortar, corresponding to mortar B of [27], whose characteristics are gathered in Tab.1. This semi-hydraulic lime provides excellent synergy with the impregnation agent and still good "breathability". Besides, its fairly low-modulus makes it especially compatible with clay or masonry support [28]. Reinforcement is provided by a square-grid carbon fabric (bi-axial reinforcing, Fig.1) whose main mechanical properties are given in Tab.2. While no dry polymer content is introduced in the matrix, bond formation is enhanced by fabric impregnation with a partially organic adhesion promoter [27]. 


\begin{tabular}{|l|c|c|}
\hline Characteristic & Unit & Value \\
\hline Yarn count & $\mathrm{tex}$ & 800 \\
Specific weight per unit fabric area & $\mathrm{g} / \mathrm{m}^{2}$ & 200 \\
Fabric specific weight & $\mathrm{g} / \mathrm{cm}^{3}$ & 1.78 \\
Grid spacing (square grid side) & $\mathrm{mm}$ & 8 \\
Carbon fabric cross-sectional area (per unit width), $A_{f}$ & $\mathrm{~mm}^{2} / \mathrm{cm}$ & 0.56 \\
Ultimate strength along the principal direction (epoxy impregnated) & $\mathrm{N} / \mathrm{cm}$ & 1800 \\
Elastic modulus & $\mathrm{GPa}$ & 240 \\
\hline
\end{tabular}

Table 2: Carbon fabric mechanical properties $(1$ tex $=9$ den $)$

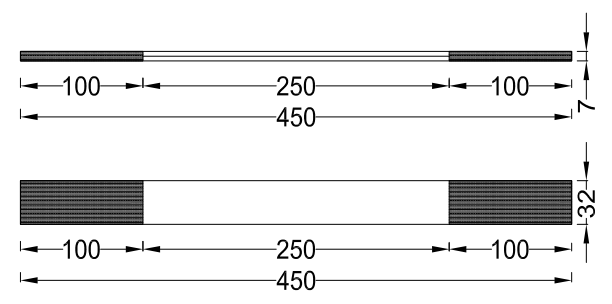

Figure 2: Composite coupon geometry

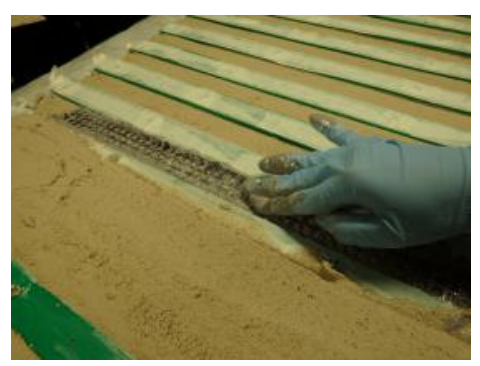

(a)

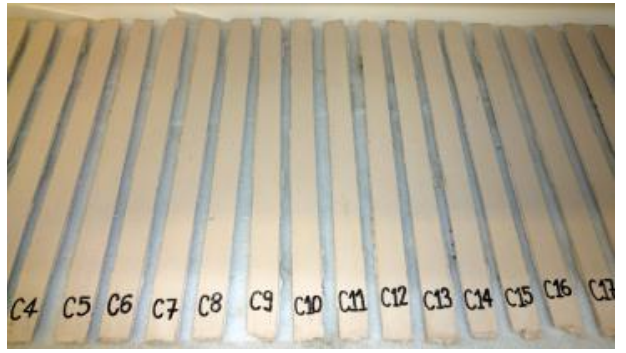

(c)

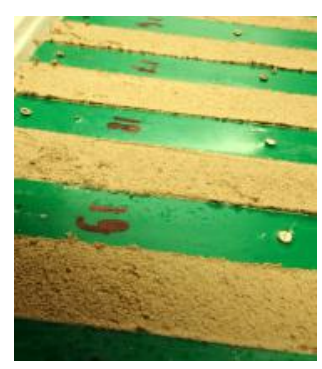

(b)

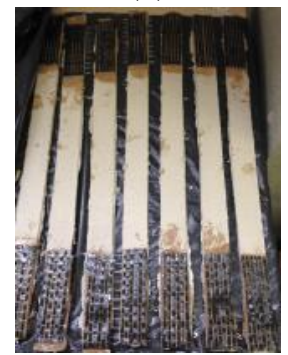

(d)

Figure 3: Specimen manufacturing: (a) impregnated reinforcement placing (b) formwork upper piece and mortar second layer (c) coupons (d) coupons with tabs 


\subsection{Composite material configuration}

Specimens are prismatic coupons of impregnated 1-ply CFRCM with rectangular cross-section (Fig.2). The specimen nominal width, $w_{s}=320$, is a multiple of the grid spacing and it accommodates 4 fabric strands [17, §A3.0]. Coupons are individually cast in a special purpose two-piece dismountable polyethylene formwork which provides reference for correct fabric reinforcement placing and allows easy and safe stripping. This procedure avoids cutting from a larger sheet, which might crack the fragile matrix and arguably enhance the negative effect of aggressive environment exposition. Indeed, according to [17, A1.0], "poor material fabrication practices, lack of control in alignment of fiber grid, and damage induced by improper cutting and machining the coupons are known causes of high material data scatter". The manufacturing process comprehends the following stages:

1. a first 3-mm-thick mortar layer is cast onto the the lubricated formwork (which consists of the bottom piece only) and a scraper is used to level it up;

2. the fabric reinforcement is cut-to-size and then impregnated by immersion in the liquid agent, the liquid in excess is shaken off the fabric which is then laid on top of the mortar layer (Fig.3a);

3. the formwork is screw-fitted on top by the upper piece which constraints the grid reinforcement into its proper position;

4. a second 3-mm-thick mortar layer is cast in the surmounting formwork (Fig.3b) and a scraper is used to level it up;

5. the formwork is wrapped in a tight plastic sheet and, after 7-day moist curing (conditioning, see [17, A5.0]), it is disassembled and specimens are strapped (Fig.3c).

Specimens are cured for either 28 or 60 days (including conditioning) in the laboratory environment and, possibly, exposed to the relevant aggressive environment. Successively, the specimen ends are fitted with $100 \mathrm{~mm}$-long carbon 


\begin{tabular}{|c|c|c|c|c|c|}
\hline \multirow[t]{2}{*}{ Environment } & \multirow{2}{*}{$\begin{array}{l}\text { Curing } \\
\text { [days] }\end{array}$} & \multirow{2}{*}{$\begin{array}{c}\text { Time } \\
\text { of exposure }\end{array}$} & \multicolumn{2}{|c|}{ Temperature } & \multirow[t]{2}{*}{ Ref. } \\
\hline & & & ${ }^{\circ} \mathrm{C}$ & $\mathrm{F}$ & \\
\hline Control (CC28/CC60) & $28 / 60$ & - & \multicolumn{2}{|c|}{ room } & - \\
\hline Saline (SW28/SW60) & $28 / 60$ & $1000 \mathrm{hrs}$ & $23 \pm 1$ & $73 \pm 2$ & [17, Table 2] \\
\hline Alkaline (AK28/AK60) & $28 / 60$ & $1000 \mathrm{hrs}$ & $23 \pm 1$ & $73 \pm 3$ & [17, Table 2] \\
\hline Acid (HA28) & 28 & $1000 \mathrm{hrs}$ & \multicolumn{2}{|c|}{ room } & [20] \\
\hline Distilled water (DW28) & 28 & $1000 \mathrm{hrs}$ & \multirow{2}{*}{\multicolumn{2}{|c|}{$\begin{array}{l}\text { room } \\
-18 / 37.7 \mid 0 / 100\end{array}$}} & {$[2]$} \\
\hline Freeze-Thaw (FT) & 28 & 20 cycles & & & {$[17, \S 4.4 .1]$} \\
\hline
\end{tabular}

Table 3: Tested environments; room temperature is $21 \pm 2^{\circ} \mathrm{C}(70 \pm 3.6 \mathrm{~F})$

fabric tabs (the prescribed minimum tab length is $75 \mathrm{~mm}$ ) which are glued to the coupon top/bottom surface with epoxy resin (Fig.3d). On the overall, 46 composite 1-ply CFRCM coupons have been fabricated for tensile testing.

\subsection{Test environments}

Tab.3 describes the environments considered in this analysis. Coupons, that have been cured for either 28-days or 60-days in the laboratory environment, are immersed in an alkaline or saline solution and then stored at constant temperature for 1000 hours $(\approx 42$ days) in a Memmert HPP110 climatic chamber [17]. The alkaline environment is a sodium bicarbonate $\left(\mathrm{NaHCO}_{3}\right)$ aqueous solution with $10 \mathrm{PH}$ level. The saline environment (saltwater resistance) is a $3.5 \%$ weight sodium chloride $(\mathrm{NaCl})$ aqueous solution, which amounts to the world's ocean seawater average salinity [1]. Following [20], to better contrast the effect of the alkaline environment, immersion in 1-molar hydrogen chloride acid solution (diluted from hydrochloric acid $\mathrm{HCl} 37 \% \mathrm{RPE}$ Carlo Erba) at room temperature is also considered (PH 2.5). Similarly, to better distinguish between the detrimental effect of low/high-PH solutions and water immersion, the effect of distilled water at room temperature has also been investigated $[2,17]$. For the latter two types of environments, plain water and $1 \mathrm{M} \mathrm{HCl}$, only 28-day cured specimens are employed. Furthermore, freeze-thaw cycles are also considered, according to which conditioned specimens are stored for 12 hours at constant temperature $\left(37.7^{\circ} \mathrm{C}\right)$ and $100 \%$ relative humidity in the climatic chamber (thaw) and then moved into a freezer $\left(-18^{\circ} \mathrm{C}\right)$ for at least 4 hours (freeze). A total of 20 freezethaw cycles have been performed $[17, \S 4.4 .1]$, after which specimens are stored 


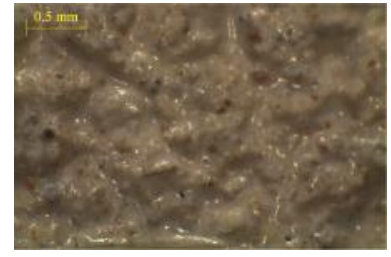

(a)

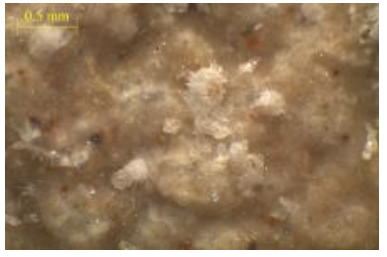

(b)

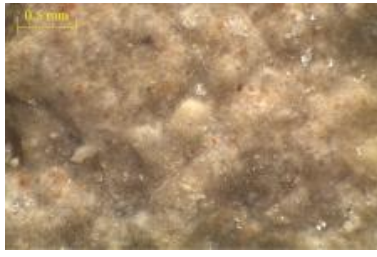

(c)

Figure 4: Optical microscopy investigation at 35x magnification: (a) control (b) saline (c) alkaline

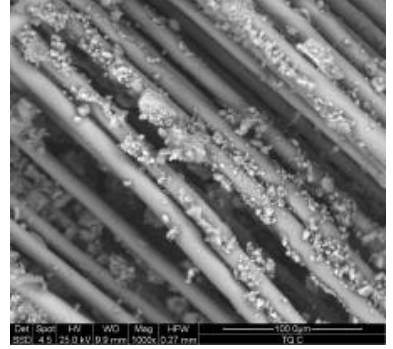

(a)

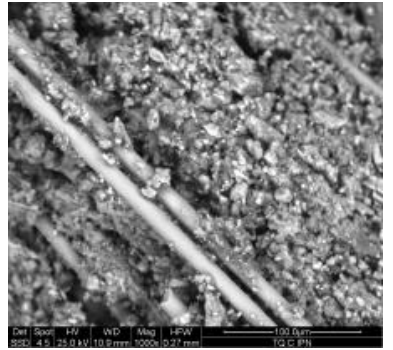

(b)

Figure 5: SEM investigation: non-impregnated (a) vs. impregnated (b) carbon fabric

at room temperature to complete the 28 -day curing period. A minimum number of 5 replicates is considered for each test environment [17, Table 1]. Besides, temperature and humidity data recording was carried out at 0.2 sample $/ \mathrm{min}$ rate for all test environments so that relevant prescribed oscillation bands could be verified.

\section{Experimental investigation}

\subsection{Conditions of acceptance}

Following $[17, \S 4.5 .2]$, control and exposed specimens have been visually examined at 5x magnification and little surface damage could be found. However, Fig.4 shows the effect of the aggressive environments on the specimen surface as it appears at 35x magnification. Indeed, the control specimen's clean and polished surface may be contrasted with the crystallized deposits and the grooves (erosion) appearing in the saline and the alkaline environments. A scanning

electron microscopy (SEM) investigation brings along the important role of the 


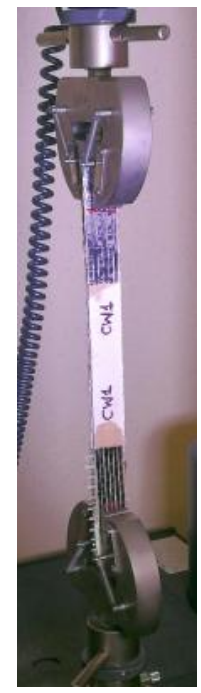

Figure 6: Test set-up (unspeckled specimen)

impregnation agent and shows that, while impregnated fabric is mostly embedded in the matrix and only a few strands emerge from it, non-impregnated fabric rests clearly separated from the matrix (Fig.5).

\subsection{Uni-axial tensile test}

Coupon performance is assessed under uni-axial tensile testing. Traction tests are performed under displacement control at a constant elongation rate of $0.5 \mathrm{~mm} / \mathrm{min}$ with an Instron 5567 machine equipped with a $30 \mathrm{kN}$ load cell and pneumatic wedge grips. This elongation rate amounts to the strain rate recommended in [31], i.e. 2 mstrain/min. Grips are connected to the machine crosshead through a spherical hinge which allows rotation in three perpendicular planes (cf.[15] for some considerations on the importance of the test set-up). A stereoscopic 3 Mpixel Dantec Dynamics Q-400 Digital Imaging Correlation (DIC) system is adopted to track the displacement field of the specimen surface speckle pattern during testing. The test set-up is shown in Fig.6.

DIC acquisition allows determining the influence of wedge grip elongation on the specimen end displacement induced by the traction machine. Fig.7 is representative of the comparison between the crosshead displacement, as measured 


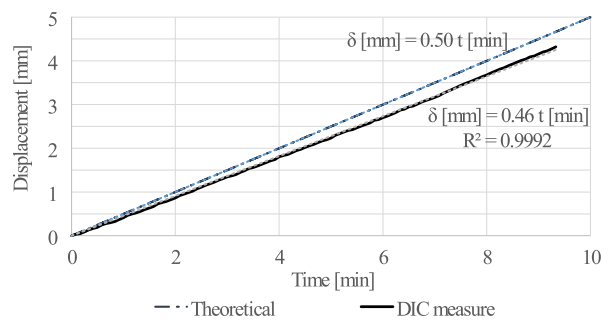

Figure 7: DIC vs imposed specimen end displacement

by the traction machine, and the actual specimen-ends' relative displacement, digitally acquired on the end tabs. It is seen that the theoretical ramp overestimates the actual specimen elongation rate by, roughly, $8 \%$, which brings in a displacement mismatch that is a linear function of time. Since no substantial deviation from this pattern could be found in the tested specimens, in the worst scenario (that is for ductile specimens, such as control's), the ultimate displacement (and strain accordingly) is overestimated by, roughly, 10\%. This correction, which is often well outside the one-standard-deviation error band, is hereinafter considered when computing the ultimate strain of the specimens and it is relevant for the correct assessment of the design limits (see $\S 4.5$ ).

Fig.8 illustrates the strength (i.e. stress-strain) curves for all specimens. Fig.9 compares the mean strength curve, evaluated from averaging the single specimen results from any specific aggressive environment, with the relevant control group's, i.e. either 28 or 60 -day curing. The sharpness of the mean stress-strain curve is indicated by embedding it in a \pm 1 standard deviation band; the fact that this band appears remarkably narrow indicates that good reproducibility was achieved. It is remarked that, according to [17, A7.0], the stress measure is conventional, inasmuch it is obtained from scaling the applied force $P$ by the fabric net area $A_{f} w_{s}$ (see formula (A3) of [17]). Similarly, the strain $\epsilon$ is obtained reporting the displacement to the coupon gauge length $\left(L_{g}=250 \mathrm{~mm}\right)[17, \mathrm{~A} 4]$. Tab.4 gathers the mean ultimate tensile strength, $\mu\left(f_{f u}\right)$, and elongation, $\mu\left(\epsilon_{f u}\right)$, with the corresponding absolute and relative standard deviation ( $R S D$ also named coefficient of variation, $C V$ ), respectively 

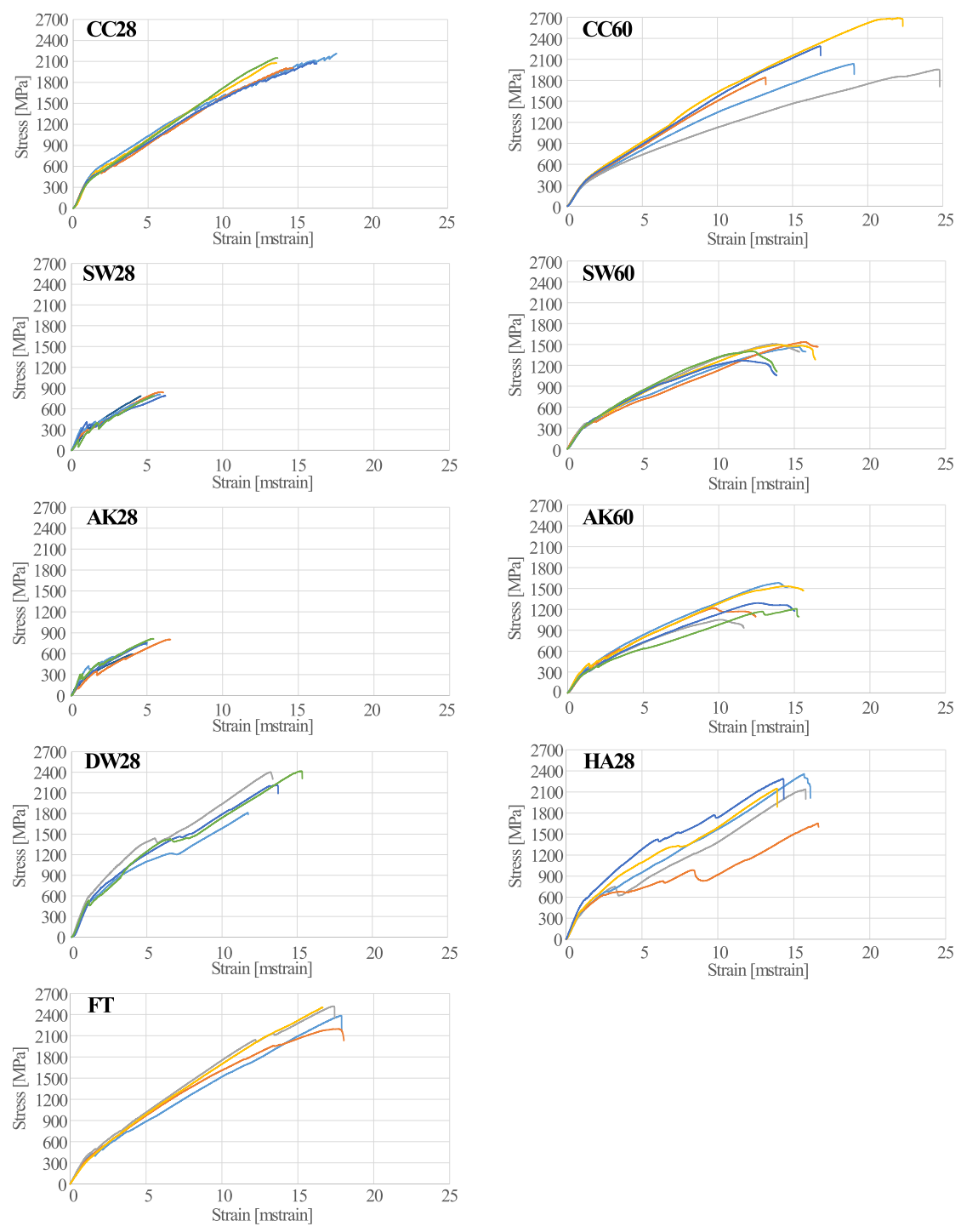

Figure 8: Stress-strain curves for all tested specimens 

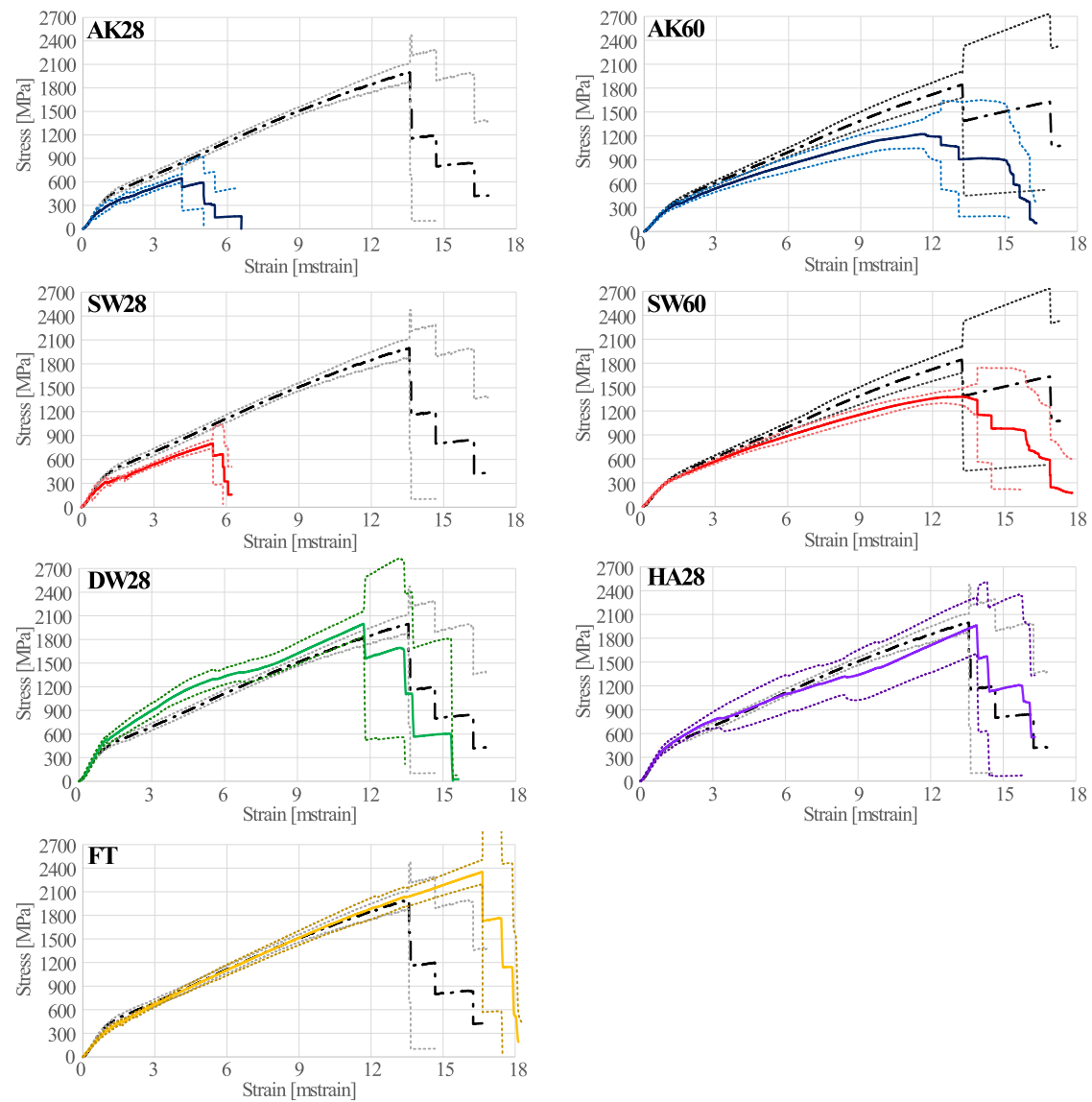

Figure 9: Mean stress-strain curves for any aggressive environment compared to the relevant control curve 


\begin{tabular}{|c|c|c|c|c|c|c|}
\hline Envs & $\begin{array}{r}\mu\left(f_{f u}\right) \\
{[\mathrm{M}}\end{array}$ & $\sigma_{f}$ & $\bar{C} C V_{f}$ & $\mu\left(\epsilon_{f u}\right)$ & $\sigma_{\epsilon}$ & $C V_{\epsilon}$ \\
\hline CC28 & 2117 & 92 & 4.3 & 1.52 & 0.19 & 12.6 \\
\hline SW28 & & 51 & 6.2 & & . & 4.5 \\
\hline AK28 & 42 & 89 & 12.0 & 0.52 & 9 & 17.0 \\
\hline AK28 & 2210 & 281 & 12.7 & 1.34 & 0.15 & 10.9 \\
\hline HA28 & 2118 & 276 & 13.0 & 1.52 & 0.11 & 7.3 \\
\hline FT & 2400 & 148 & 6.2 & 1.73 & 0.05 & 2.9 \\
\hline CC60 & 162 & 337 & 15.6 & 1.92 & 0.44 & 23.1 \\
\hline SW60 & & 106 & 7.4 & 1.41 & 0.12 & 8.4 \\
\hline AK60 & 1313 & 220 & 16.8 & 1.27 & 0.22 & 17.2 \\
\hline
\end{tabular}

Table 4: Mean ultimate tensile strength $\mu\left(f_{f u}\right)$ and elongation $\mu\left(\epsilon_{f u}\right)$, with respective standard deviations, $\sigma$, and coefficient of variation, $C V$, for all test environments (Envs) of Tab.3

$\sigma$ and $C V=\sigma / \mu$, for all test environments.

\section{Results and discussion}

\subsection{Longitudinal elastic moduli and first cracking strength}

The mean stress-strain curves allows determining the longitudinal elastic modulus for the uncracked, $E_{f}^{*}$, and the cracked, $E_{f}$, specimen [17, A7.5/6]. Such moduli are determined from the strength curve through linear-fitting of the conventional points given in $[3,27]$. In light of the matrix cross-sectional area $A=w_{s} h_{s}$ (here $h_{s}=7 \mathrm{~mm}$ is the specimen nominal thickness) being much larger than the fabric's $A_{f} w_{s}$, a corrected uncracked modulus is sometimes introduced [3]

$$
E_{1}^{*}=E_{f}^{*} \frac{A_{f} w_{s}}{A}
$$

which should better express the mechanical stiffness of the coupon before matrix cracking occurs. Fig.10 shows that the longitudinal elastic moduli $E_{f}^{*}$ and $E_{f}$, evaluated from the mean strength curve, provide a very accurate description of the composite stress-strain behavior before and after the cracking of the brittle matrix, respectively (see the coefficient of determination $r^{2}$ given in Tab.5 for the cracked regime). The transition from the uncracked to the cracked regime occurs at the so-called transition point $T$, whence its ordinate is often named first cracking resistance. Tab.5 gathers the mean $\mu$ and the coefficient of variation $C V$ for the elastic moduli and for the transition point location when they 

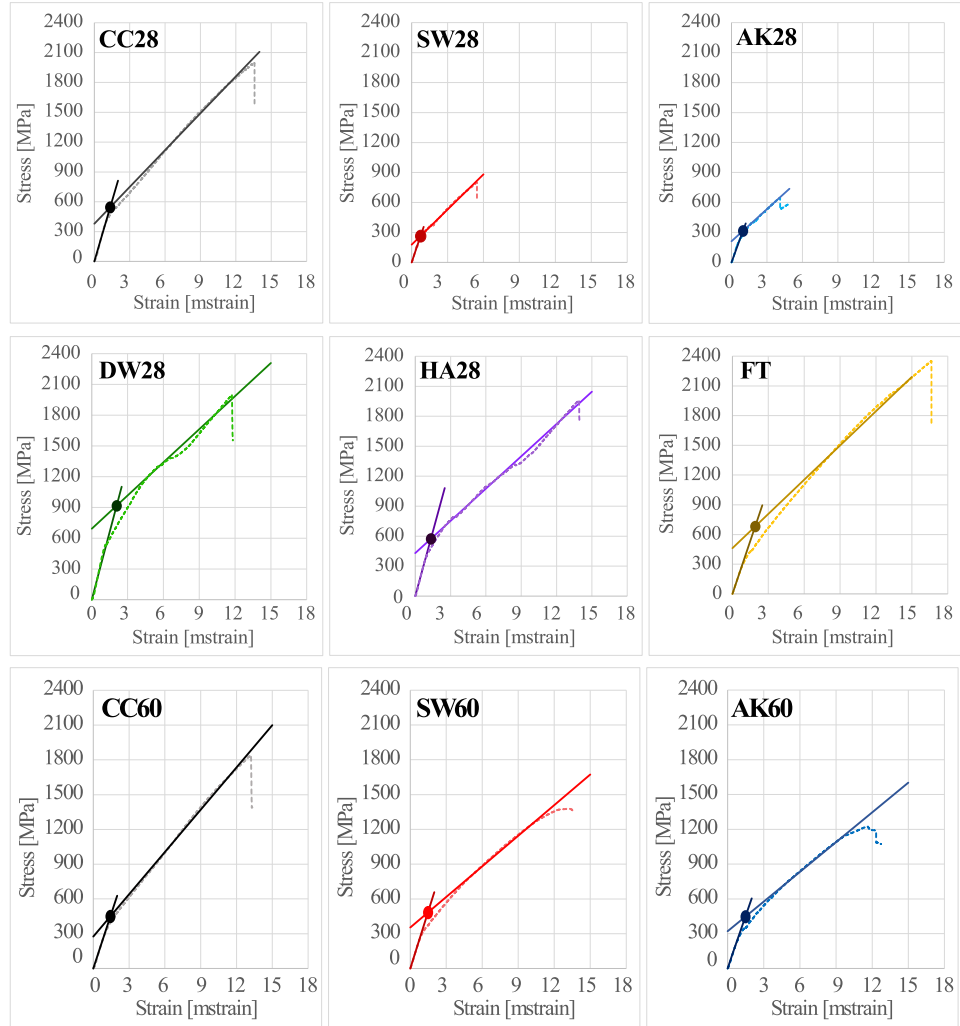

Figure 10: Location of the transition point $T$, evaluated from the mean stress-strain curve, for 28- and 60-day cured specimens

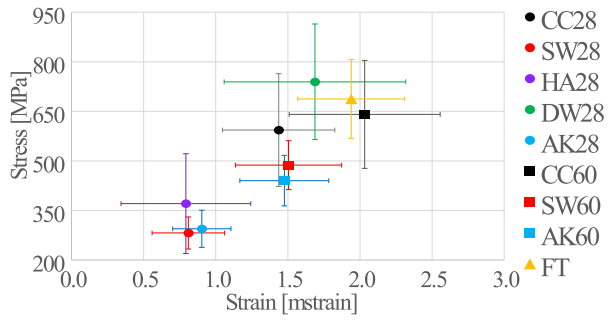

Figure 11: Transition point location and one-standard-deviation bars for stress and strain 


\begin{tabular}{|c|c|c|c|c|c|c|c|c|c|c|}
\hline \multirow[t]{2}{*}{ Envs } & $E_{1}^{*}$ & \multicolumn{2}{|c|}{$E_{f}^{*}$} & \multicolumn{3}{|c|}{$E_{f}$} & \multicolumn{2}{|c|}{$\epsilon_{T}$} & \multicolumn{2}{|c|}{$f_{T}$} \\
\hline & & & $\begin{array}{c}C V \\
\%\end{array}$ & $\begin{array}{c}\mu \\
{[\mathrm{GPa}]}\end{array}$ & $\begin{array}{l}C V \\
{[\%]}\end{array}$ & $\begin{array}{l}r^{2} \\
{[-]}\end{array}$ & $\mu$ & $C V$ & $\begin{array}{c}\mu \\
{[\mathrm{MPa}]}\end{array}$ & $\begin{array}{l}C V \\
{[\%]}\end{array}$ \\
\hline CC28 & 3.8 & 413 & 8.1 & 117 & 17.8 & 0.929 & 0.14 & 27.1 & 593 & 28.8 \\
\hline SW28 & 3.4 & 364 & 21.7 & 114 & 13.6 & 1.022 & 0.08 & 31.0 & 282 & 17.2 \\
\hline AK28 & 3.1 & 332 & 16.1 & 110 & 7.7 & 0.915 & 0.09 & 22.3 & 295 & 19.1 \\
\hline DW28 & 4.2 & 456 & 17.2 & 123 & 16.1 & 0.867 & 0.17 & 37.3 & 739 & 23.7 \\
\hline HA28 & 4.0 & 435 & 13.0 & 120 & 12.4 & 0.995 & 0.08 & 56.8 & 371 & 40.7 \\
\hline FT & 3.3 & 357 & 10.5 & 115 & 9.1 & 0.961 & 0.19 & 19.1 & 688 & 17.3 \\
\hline CC60 & 2.9 & 316 & 3.8 & 98 & 25.5 & 0.952 & 0.20 & 25.7 & 641 & 25.5 \\
\hline SW60 & 3.1 & 331 & 11.8 & 88 & 6.8 & 0.981 & 0.15 & 24.5 & 487 & 15.2 \\
\hline AK60 & 2.8 & 303 & 14.8 & 87 & 10.9 & 0.957 & 0.15 & 20.9 & 440 & 17.4 \\
\hline
\end{tabular}

Table 5: Mean moduli $E_{1}^{*}, E_{f}^{*}, E_{f}$ and transition point $(T)$ location $\left(C V\right.$ and $r^{2}$ are the coefficient of variation and of determination, respectively) evaluated from each stress-strain curve within a given environment

are calculated for each experimental stress-strain curve within a given environment. It is emphasized that, in the lack of specific indication from the guidelines, moduli and transition point location determined from the mean strength curve are to be preferred over taking the average of the corresponding quantities calculated for each experimental curve. Indeed, the former procedure is less sensitive to experimental error, in consideration of the conventional nature of the definitions of $E_{f}, E_{f}^{*}$ and $T$ which make use of single points on the stress-strain curve. Fig.11 shows the uncertainty connected with the determination of the transition point for each stress-strain curve within the considered environment in terms of one standard deviation bars. In contrast to the results obtained for glass fabric composites [27], the corrected uncracked elastic modulus $E_{1}^{*}$ largely underestimates the matrix elastic modulus of Tab.1. In a similar manner and similarly to the results for glass fabric composites, the cracked modulus $E_{f}$ underestimates the carbon fabric elastic modulus. However, moduli and transition point location for the control environment closely resemble the analogous results presented in [10, Tab.8], despite a stronger (yet more brittle) matrix was there considered. 


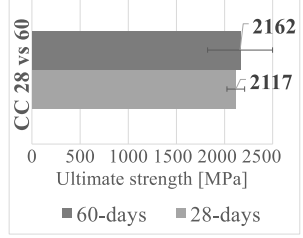

(a)

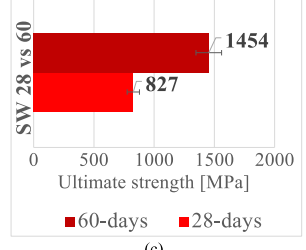

(c)

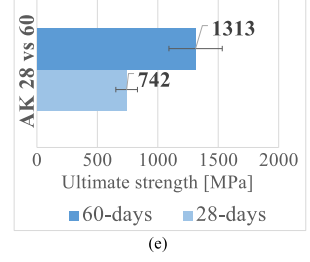

Figure 12: Ultimate strength (left) and elongation (right panel) 28-vs. 60-day-curing-time bar chart comparison: $(\mathrm{a}, \mathrm{b})$ control $(\mathrm{c}, \mathrm{d})$ saline $(\mathrm{e}, \mathrm{f})$ alkaline environments

\subsection{Effect of the curing time}

To better illustrate the important role of curing time in affecting the aggressive environment resistance, ultimate tensile strength and elongation values are illustrated in the bar charts of Fig.12 for the control, saline and alkaline environments, for which 28- and 60-day curing times are available. Although the small increment in the ultimate strength and elongation which is seen in the control group at 60-day with respect to 28-day curing time appears of little statistical significance (cf.[25, §13]), the corresponding improvement in the saline and in the alkaline environment is truly remarkable. Indeed, it appears that early-stage exposure to the aggressive environment determines a $60 \%$ and $65 \%$ decay in the ultimate strength, respectively for the saline and alkaline environments, as opposed to a $32 \%$ and $39 \%$ decay for later-stage exposure. Similar results attain the ultimate elongation, with a reduction in the order of $64 \%$ for both environments, to be compared with $28 \%$ and $33 \%$ at later-stage. These 


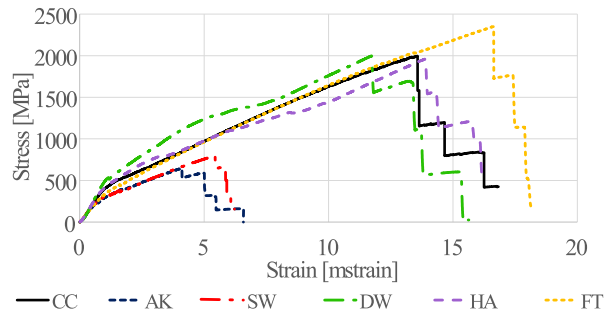

Figure 13: Mean stress-strain curve of the control, alkaline, saline, distilled water, HCl-acid environments and freeze-thaw cycles for 28-day cured specimens
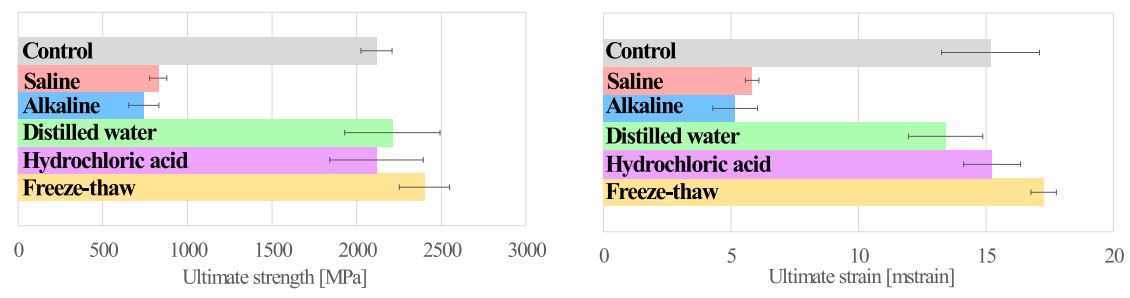

Figure 14: Mean ultimate stress (left) and ultimate strain (right) for 28-day cured specimens

results follow in the wake of a vast body of literature confirming the important role of curing time on concrete porosity and resistance to penetration of aggressive agents $[14,34]$. It is worth mentioning that curing time appears to have little effect on the relative standard deviation for the ultimate strength in the aggressive environments (while the same no longer holds true for the ultimate elongation, whose determination, however, is generally less accurate).

\subsection{Aggressive environments comparison}

Fig.13 shows the mean stress-strain curves for all environments at 28-day curing time. The effect of the different aggressive environments on the specimen
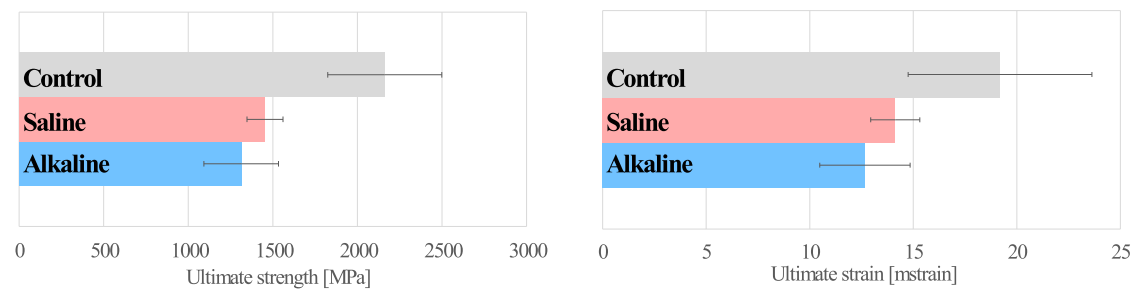

Figure 15: Mean ultimate stress (left) and ultimate strain (right) for 60-day cured specimens 
ultimate stress and ultimate strain is better illustrated through the bar charts of Fig.14 and 15, respectively for 28- and 60-day cured specimens. It clearly appears that a substantial strength reduction is produced by the saline and the alkaline environments, which is particularly pronounced for 28-day cured specimens. This is in agreement with the corresponding results obtained for ar-glass fabric reinforced composites [27] and particularly for the alkaline environment, wherein performance degradation is attributed to formation of a new solid phase at the matrix/fabric interface and not to glass fabric deterioration $[16,8,9]$. Indeed, the mean ultimate tensile strength for the saline and alkaline environments for glass as well as carbon fabric reinforced composites are very similar, which suggests that the composite's performance decay is mostly due to matrix/fabric bond degradation and it is little responsive to the nature of the reinforcement. As a result, owing to its superior mechanical property in the control environment, carbon fabric composite performance degradation appears much greater than glass fabric composite's. It is further observed that an opposite trend is described in [3, Appendix D], wherein the alkaline and the saline environments appear to have a beneficial or neutral effect on the first cracking resistance, $f_{T}$, and on the ultimate tensile strength, $f_{f u}$, as compared to the control group's.

Immersion in distilled water, hydrochloric acid and freeze-thaw cycles seem to have little effect on the strength curve, the statistical significance of which is assessed through a one-way ANalysis of Variance (ANOVA) [24, 27]. ANOVA assumes a normal distribution in the specimen groups and a Behrens-Fisher distribution for the corresponding variance evaluated within the groups. Tab.6 shows the Fisher-Snedecor ratio, $F$, as well as the probability confidence, $P$, that different specimens really belong to the same population (this is the null hypothesis, which is associated with $P>1$ ). It appears that some statistical support, albeit weak, is attached to a real influence of these aggressive environments on the composite performance. In particular, the performance enhancement obtained for freeze-thaw exposed specimens with respect to the control group possesses statistical significance. On the other hand, inasmuch as 


\begin{tabular}{|l|c|c|}
\hline Null hypothesis for the ultimate strength & $F$ & $P$ \\
\hline CC28, DW28, HA28, FT $\in$ s.p. & 1.6629 & $21.9 \%$ \\
CC28, DW28, HA28 $\in$ s.p. & $\mathbf{0 . 2 3 7 8}$ & $79.2 \%$ \\
DW28, HA28, FT $\in$ s.p. & 1.484 & $27.3 \%$ \\
\hline Null hypothesis for the ultimate strain & $F$ & $P$ \\
\hline CC28, DW28, HA28, FT $\in$ s.p. & 5.005 & $1.5 \%$ \\
CC28, DW28, HA28 $\in$ s.p. & 1.905 & $19.5 \%$ \\
DW28, HA28, FT $\in$ s.p. & 11.870 & $0.2 \%$ \\
\hline
\end{tabular}

Table 6: ANOVA test results: $F$ - Fisher-Snedecor ratio, $P$ - Probability confidence, s.p.same population. The null hypothesis is rejected whenever $F>1$

ultimate strength is concerned, ANOVA suggests that control, distilled water and hydrochloric acid exposed specimens really belong to the same population. This outcome is especially interesting with respect to the $\mathrm{HCl}$-acid solution, which exhibits a highly detrimental influence on the mechanical performance of FRP composite [20]. Conversely, the neutral effect of distilled water immersion is compatible with the semi-hydraulic nature of the adopted mortar.

\subsection{Crack pattern and failure mechanism}

The specimen displacement field gives good indications on crack progression to failure. Fig.16 shows the crack opening pattern at the same elongation level $\epsilon=0.55 \%$ for all the considered environments. It may be seen that control, acid, distilled water and freeze-thaw exposed specimens are characterized by several multiple small cracks developing across the specimen, so that numerous uniformly-colored bands appear along the specimen length, each expressing the displacement of a fragment of uncracked mortar. In contrast, alkaline and saline specimens show fewer and bigger cracks marking the limits of 5 or 6 uniformlycolored bands. This behavior is better illustrated in Fig.17 which compares the longitudinal displacement along the coupon axis at different elongations for the control, saline and alkaline environments. In Fig.17, displacement jumps amount to crack openings. As it is well known, a diffused cracking texture is generally desirable for it warrants ductility and energy absorption capability.

A measure of (dimensionless) average crack spacing vs. strain is given in Fig.18, which illustrates the different levels of crack saturation attained by the 


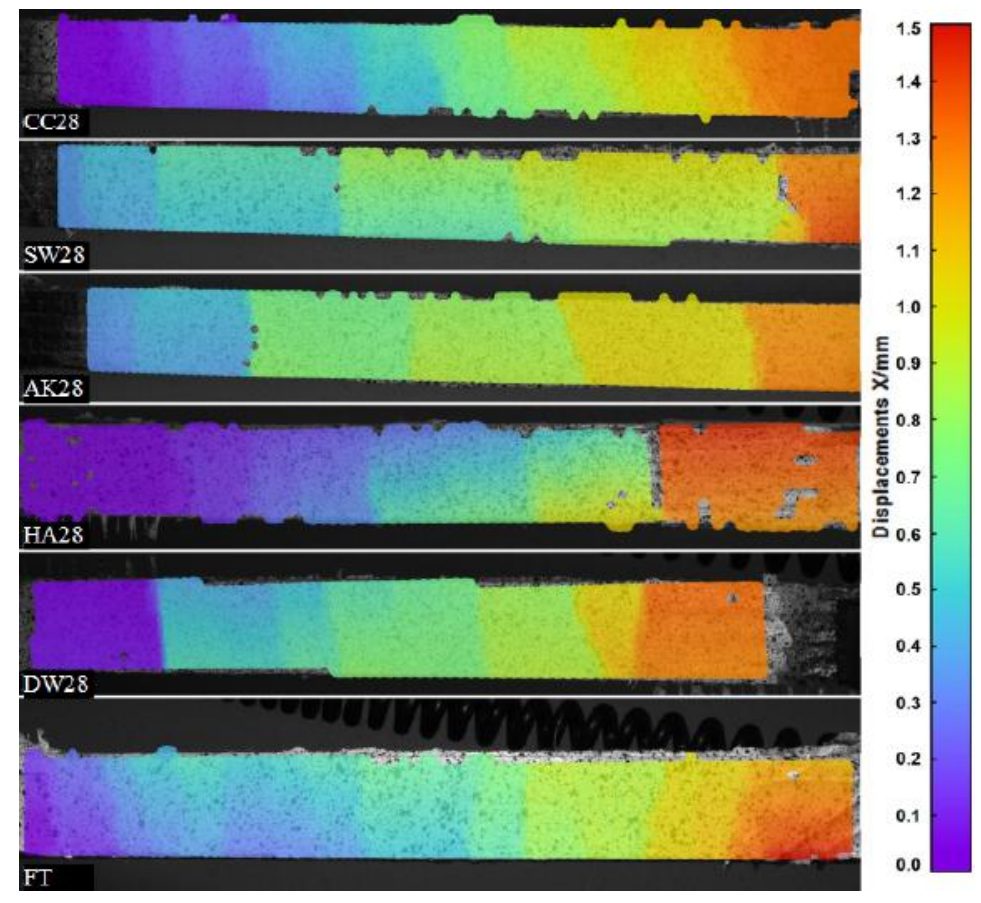

Figure 16: Crack opening pattern at $\epsilon=0.55 \%$

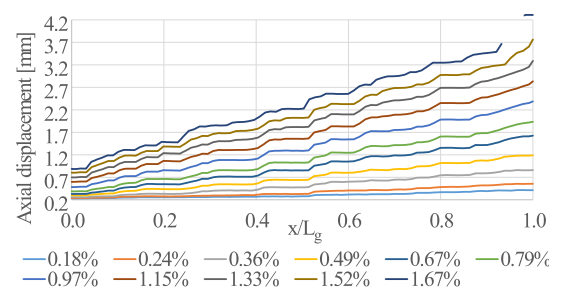

(a)

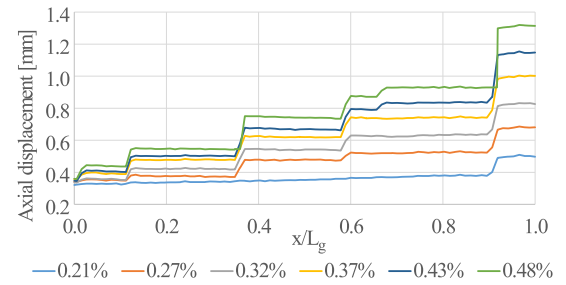

(c)

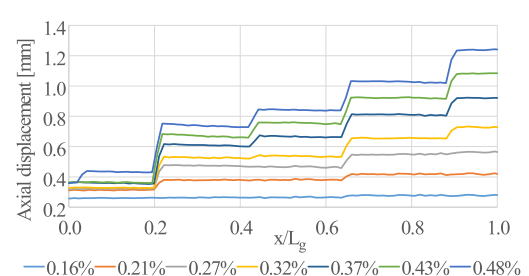

(b)

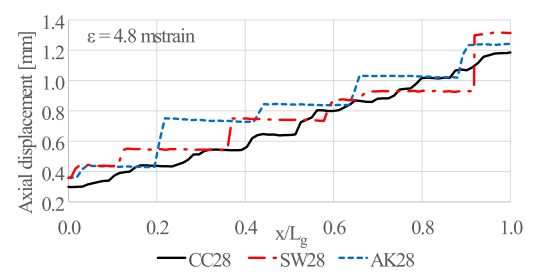

(d)

Figure 17: Longitudinal displacement at the coupon axis at different strain levels for CC28 (a), SW28 (b), AK28 (c) and comparison at $\epsilon=0.48 \%$ (d) 


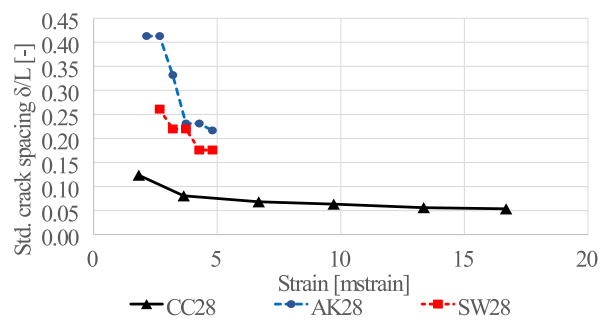

Figure 18: Dimensionless mean crack spacing vs. strain

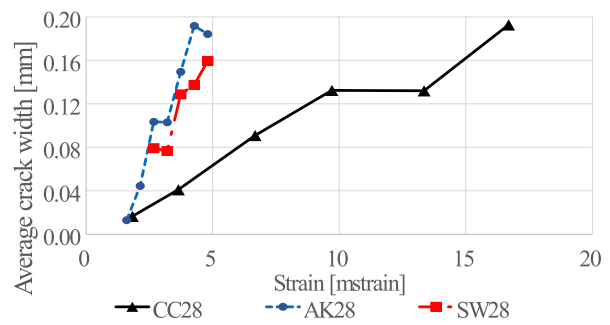

Figure 19: Mean crack width vs. strain
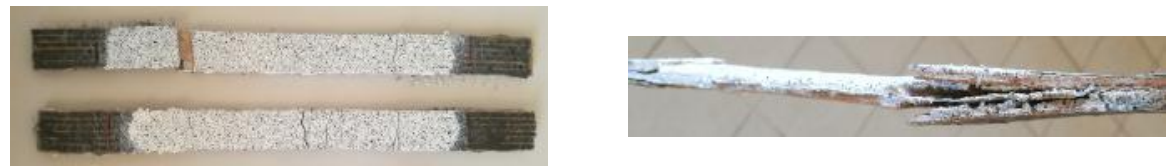

Figure 20: Failure mechanism (left) and fabric slippage (right) 
exposed specimens compared to the control ones. Crack spacing is indirectly related to matrix/fabric bond strength, to the composite stiffness and to durability aspects [25]. Besides, digital image analysis allows plotting the average crack width against strain (Fig.19). This plot is remarkable in that it shows that, unlike crack spacing, the mean crack width increases with the strain until it reaches a maximum value (saturation) which is independent of the environmental exposure.

In all cases, failure is due to delamination as a result of crack spacing saturation, whereby a dominant crack (usually but not always located near the end of any one tab) propagates inside the specimen at the fabric/mortar interface [26]. Fabric failure could never be reached (Fig.20).

\subsection{Design considerations}

$[17, \S 8.0]$ provides minimum acceptable design criteria for the design of FRCM strengthening which allow assessing the mechanical bearing capacity of the composite system. When failure of the composite system is due to tensile rupture of the FRCM material, the flexural strength enhancement to both masonry and reinforced concrete (RC) members is limited by the design tensile strain

$$
\epsilon_{f d}=0.7 \epsilon_{f u} \leq 1.2 \%
$$

wherein $\epsilon_{f u}$ is the ultimate tensile strain of the composite material. The latter is obtained through the so-called three-sigma rule, namely

$$
\epsilon_{f u}=\mu\left(\epsilon_{f u}\right)-3 \sigma
$$

and it cannot exceed the $5 \%$ fractile of the capacities obtained experimentally, i.e. the characteristic value, which, for normally distributed populations, is given by

$$
\epsilon_{f u k}=\mu\left(\epsilon_{f u}\right)-1.96 \sigma .
$$

The effective tensile stress level in the composite follows through the cracked longitudinal modulus $E_{f}$ as

$$
f_{f e}=0.85 E_{f} \epsilon_{f e},
$$




\begin{tabular}{|c|c|c|c|c|c|c|c|c|}
\hline Envs & $\overline{\epsilon_{f u}}$ & $\begin{array}{l}\epsilon_{f_{u k}} \\
{[\%]}\end{array}$ & $\epsilon_{f d}$ & $\begin{array}{l}\gamma_{m}^{\prime} \\
{[-]}\end{array}$ & $f_{f e}$ & $\begin{array}{c}f_{T} \\
{[\mathrm{MPa}}\end{array}$ & $f_{f e k}$ & $\begin{array}{l}\gamma_{m} \\
{[-]}\end{array}$ \\
\hline CC28 & 0.94 & 1.35 & 0.66 & 2.06 & 619 & 554 & 2022 & 3.27 \\
\hline SW28 & 0.50 & 0.55 & 0.35 & 1.58 & 316 & 265 & 788 & 2.49 \\
\hline AK28 & 0.26 & 0.43 & 0.18 & 2.38 & 149 & 316 & 622 & 4.18 \\
\hline DW28 & 0.90 & 1.19 & 0.63 & 1.89 & 524 & 573 & 1872 & 3.57 \\
\hline HA28 & 1.19 & 1.40 & 0.83 & 1.68 & 714 & 912 & 1750 & 2.45 \\
\hline FT & 1.58 & 1.67 & 1.10 & 1.51 & 985 & 682 & 2225 & 2.26 \\
\hline CC60 & 0.58 & 1.40 & 0.41 & 3.43 & 385 & 437 & 1864 & 4.84 \\
\hline SW60 & 1.08 & 1.30 & 0.76 & 1.71 & 516 & 483 & 1302 & 2.52 \\
\hline AK60 & 0.57 & 0.98 & 0.40 & 2.44 & 267 & 448 & 1090 & 4.09 \\
\hline
\end{tabular}

Table 7: Ultimate tensile elongation $\epsilon_{f_{u}}$ and design values for all test environments

where $\epsilon_{f e} \leq \epsilon_{f d}$ and equality holds at failure. From a methodological viewpoint, this approach can be confronted with the strength design protocol [18], as coded in [19] for FRP materials, which makes use of the characteristic value of the material strength further divided by the material partial factor $\gamma_{m}$ (also known as safety factor or strength reduction factor), i.e.

$$
R_{d}=\eta \frac{f_{f c k}}{\gamma_{m}}
$$

where $\eta=\eta_{a} \eta_{l}$ is the conversion factor which comprises the effect of environmental exposure and long-term effects, respectively. Partial factors $\gamma_{m}$ for FRP material depend on the limit state under consideration and, in the case of the ultimate limit state (ULS), they vary with the envisioned rupture mechanism in the range 1.10-1.50 [19, Tab.3-2]. For the serviceability limit state (SLS), it is taken $\gamma_{m}=1$. A similar approach is described in [23] in the more general context of Continuous Fiber Reinforcing Materials (CFRM) to which FRCM composite belongs, although specific reference is there restricted to organic binders (epoxy or vinyl-ester resin) typical of FRP.

Tab.7 gathers the ultimate tensile strain along with the characteristic and the design ultimate strain as well as the ultimate and characteristic strength at failure. It may be seen that consideration of the ultimate design strain $\epsilon_{f d}$ to determine the design strength at failure, according to (3), greatly underestimates the experimental mean $\mu\left(f_{f u}\right)$, to the extent that the design strength 
often falls in the proximity of or even prior to the first cracking resistance $f_{T}$. This result, which comes about despite the design strain limit at failure, $\epsilon_{f d}$, being much greater than the first cracking strain, $\epsilon_{T}$, entails from considering only the cracked modulus $E_{f}$ in Eq.(3) and neglecting the initial contribution of the uncracked modulus $E_{f}^{*}$. In this respect, the bi-linear behavior characteristic of FRCM materials (the tri-linear behavior advocated in [10] is not matched in our results) is really replaced with a linear law, which is the typical behavior assumed for FRP (see, for instance, [23, §3.4.3] and [19, §2.3.1]). Besides, we remark that the three-sigma rule is a very cautionary provision when applied to the ultimate strain, for its determination is often connected to a bigger experimental uncertainty as compared to the ultimate strength (see, for instance, the dispersion of the experimental results presented in $[27,10])$. As a result, the ultimate design strength, as evaluated on the basis of the ultimate design strain, for the control environment and for 60-day cured specimens, is $37.8 \%$ smaller than the corresponding strength deduced from 28-day cured specimens, whereas the corresponding comparison on the characteristic values yields a mere $7.8 \%$ reduction. It is remarked that this outcome, although specific to this experimental sample, is believed to be general, as bigger relative standard deviation bands usually accompany higher-mean samples (the same experimental trend is casually observed in [10]). This phenomenon, called positive covariance, occurs because small imperfections, which are ineffective in weak specimens, tend to play an important role in the failure of tougher specimens [24]. Indeed, no exception to this rule may be found in our data. The same considerations carry over, with little modification, when considering a deformation limit, for then the design strain limit is $[19, \S 4.2 .2]$

$$
\epsilon_{f d}=\eta_{a}^{\prime} \frac{\epsilon_{f u k}}{\gamma_{m}^{\prime}}
$$

where $\gamma_{m}^{\prime}$ and $\eta_{a}^{\prime}$ are really equal to, respectively, $\gamma_{m}$ and $\eta_{a}$ in the codes.

Tab.7 lists the partial factors $\gamma_{m}^{\prime}$ and $\gamma_{m}$ for all the test environments. $\gamma_{m}$ is determined as the partial factor which reduces the material resistance, $R_{d}$, to the design strength $f_{f e}$, as obtained from Eqs.(4) and (3), respectively (take $\eta=1$ ). 
It is straightforward to see that operating on the basis of the characteristic strength yields the same result as operating from the design strain inasmuch as exceedingly large values (compared with those introduced for FRP materials) for the partial factor $\gamma_{m}$ are assumed, falling in the range 2.26-4.84. Likewise, the partial factor $\gamma_{m}^{\prime}$, which makes the design ultimate strain $\epsilon_{f d}$ evaluated according to (5) correspond to the limit given by (1), lies in the range 1.513.43 and its maximum is attained for 60-day cured specimens in the control environment. It may be argued that this is a consequence of the adoption of a brittle matrix, which requires bigger safety factors to avert the danger of sudden failure. However, characteristic value design applies equally well to brittle failure, such as it occurs in shear induced collapse, and, generally, FRP materials undergo fragile rupture.

When exposure to aggressive environments is envisaged, such is the case in sea-front constructions, bridge decks and quays, industrial plants, storage tanks etc., and in the absence of experimental data on the exposed FRCM system, the design procedure illustrated in [17] is no longer available. This shortcoming can be amended by the knowledge of the environmental conversion factors $\eta_{a}, \eta_{a}^{\prime}$ of interest, through which the design parameters of the standard composite material may be safely reduced to accommodate for the detrimental effect of the environment. The available experimental data allows determining the environmental conversion factor $\eta \leq 1$ for the test environments by two formally different methods. They are illustrated with reference to the ultimate strength (resistance):

(a) By the first procedure, conversion factors are determined in the spirit of [19, $\S 3.5 .1]$ as the ratio between the characteristic strength in the environment of interest and the characteristic strength in the control environment for the same curing time

$$
\gamma_{m}^{(a)}=\frac{f_{f e k, \text { exposed }}}{f_{f e k, \text { control }}}
$$

From a statistical standpoint, this method guarantees that the $5 \%$-fractile of the population sample strength is retrieved. However, it should be remarked 


\begin{tabular}{|l|c|c|c|c|c|}
\hline Envs & Curing & \multicolumn{2}{|c|}{$\eta_{a}[\%]$} & \multicolumn{2}{c|}{$\eta_{a}^{\prime}[\%]$} \\
& [days] & (a) & (b) & $(\mathrm{a})$ & $(\mathrm{b})$ \\
\hline SW28 & & 39 & 35 & 41 & 32 \\
AK28 & \multirow{2}{*}{28} & 31 & 28 & 32 & 26 \\
DW28 & & 93 & 84 & 88 & 72 \\
HA28 & & 87 & 77 & $(103)$ & 80 \\
\hline FT & & $(110)$ & $(102)$ & $(124)$ & 95 \\
\hline SW60 & \multirow{2}{*}{60} & 70 & 53 & 93 & 55 \\
AK60 & & 84 & 45 & 70 & 42 \\
\hline
\end{tabular}

Table 8: Environmental conversion factors for the test environments calculated according to method (a) and (b). Numbers in parenthesis are to be ceiled at the maximum allowed value of $100 \%$

that here the considered population sample is restricted to the exposed specimens.

(b) The second procedure treats all possible strength ratios between the exposed and the control environment specimens (for the same curing time) as a new population sample, whose $5 \%$-fractile is then determined, i.e.

$$
\gamma_{m}^{(b)}=5 \% \text {-fractile of }\left\{\frac{f_{f e, i}}{f_{f e, j}}\right\} \quad \text { for any pair }(i, j) \in N \times N \text {. }
$$

Conceptually, this method is more sound as it provides the $5 \%$-fractile of a bigger population sample, which consists of all possible permutations of the performance decay ratios. In this sense, according to this method, $\gamma_{a}$ is a covariant quantity of two population samples. As a result of considering a bigger sample size, this method provides smaller factors.

By analogy, the same procedure may be applied to determine the conversion factor for the design strain, $\eta_{a}^{\prime} \leq 1$. The environmental conversion factors, as calculated according to both methods, are gathered in Tab.8. For the sake of comparison, they can be confronted with $\eta_{a}=85 \%$ proposed in [19] for resistance of carbon/epoxy in a general aggressive environment and with the $70 \%$ strength loss reported in [20] for ar-glass FRP composites in acid and alkali solutions (see also [21] for FRP long-term seawater resistance). Remarkably, the conversion factors for strength and strain are very similar when calculated according to method (b). Similarly to strength ratios, which provide a measure of 
structural safety, they furnish a very convenient indication of the FRCM system vulnerability to a given aggressive environment. Finally, some word of caution should be spent on the identification of the characteristic quantities, usually obtained from Eq.(2), with the 5\%-fractile of the population distribution, for this is indeed the case for normally distributed populations only. As it can be seen from the frequency bar charts of [10], experimental data are often far from being normally distributed. In this sense, simply referring to the two-sigma rule would be more appropriate.

\section{Conclusions}

In this study, the effect of the aggressive environment and of the curing time on the mechanical performance of impregnated carbon-FRCM prismatic coupons is assessed according to the ICC guidelines. Specimens have been subjected to 5 aggressive environments, namely seawater, alkaline, distilled water, hydrochloric acid and freeze-thaw cycles, and two curing times: 28 and 60 days. Emphasis is placed on determining the design limits for all test environments from the experimental data and following ICC minimum design criteria. The following results are especially worthy of consideration:

- aggressive environments may significantly reduce the design limits and should be carefully considered; in particular, the seawater and the alkaline environments are especially demanding in terms of performance degradation, while distilled water and hydrochloric acid produce no statistically significant effect (under ANOVA test); finally, freeze-thaw cycles induce a small beneficial effect.

- These results set some interesting application ranges for FRCM in contrast to FRP, the latter being more suitable for seawater conditions, the former for acid environments, both suffering in alkali [20];

- compared to 28-day cured samples, 60-day curing time produces little effect on the limit properties of the unexposed specimen, yet it is capable 
of greatly mitigating the impact of the aggressive environments with a beneficial effect close to $30 \%$ of the unexposed value;

- consequently, early-stage protection of the composite material should be always considered in an aggressive environment;

- the crack pattern (spacing) measured along tensile uni-axial testing provides strong evidence of the mechanical performance of the matrix and of the matrix/fabric bond: in degraded specimens, the closely-spaced array of tiny cracks typical of the control environment is replaced by a coarse arrangement of bigger cracks and this markedly different behavior is evident at all stages of the test. In this sense, uni-axial testing of composite samples may represent a good test candidate for material qualification.

- Conversely, mean crack width is a monotonic increasing function of strain whose maximum, attained at failure, appears independent of environmental exposition.

- Design limits determined by the two-sigma rule and subsequent application of a safety factor, as prescribed in several codes dealing with FRP strengthening, are to be preferred over limits determined by the threesigma rule, for the latter is strongly based by the positive covariance effect;

- as a result, design limits evaluated according to the three-sigma rule for longer-term-cured specimens substantially differ from and indeed are smaller than the corresponding limits evaluated from shorter-term-cured specimens.

Environmental conversion factors are introduced following two statistically different procedures, named (a) and (b), as a mean to easily and safely assess the detrimental effect of an aggressive environment on the mechanical properties of the composite. Indeed, they allow reducing the unexposed composite design limits to the corresponding ones pertaining to the exposed material at the same curing time. In this sense, environmental conversion factors should 
be given for different aggressive environments, specimen curing time and design limit. In particular, method (b) proves to be safest and yields almost equal results for stress and strain limits. Finally, we emphasize that the experimental results presented in this analysis should be regarded as a qualitative guideline for further experimentation, as they are specific to a single mortar (adopted in the strengthening project illustrated in [28]). However, allowing for different mortar properties, the qualitative trend should remain the same [9], on the grounds that variations in the test set-up, with special regard to gripping, specimen preparation and uni-axial test specifications, may also significantly alter the quantitative results but still preserve the qualitative behavior.

\section{Acknowledgments}

Financial support form the Fondazione Cassa di Risparmio di Modena, Pratica Sime nr.2013.0662, is gratefully acknowledged. The authors wish to mention the contribution of Lisa Barilli and Giorgia Martinelli in specimen preparation.

[1] American Society for Testing and Materials (ASTM). Standard practice for the preparation of substitute ocean water. D 1141, 1998.

[2] American Society for Testing and Materials (ASTM). Standard practice for testing water resistance of coatings in $100 \%$ relative humidity. D 2247, 2002.

[3] Arboleda D. Fabric Reinforced Cementitious Matrix (FRCM) Composites for Infrastructure Strengthening and Rehabilitation: Characterization Methods. PhD thesis, University of Miami, 2014. Open Access Dissertation. Paper 1282.

[4] Arboleda D, Babaeidarabad S, Hays C, and Nanni A. Durability of fabric reinforced cementitious matrix (FRCM) composites. CICE 2014, 2014. Vancouver, 20-22 August 2014. 
[5] Banholzer B, Brockmann T, and Brameshuber W. Material and bonding characteristics for dimensioning and modelling of textile reinforced concrete (TRC) elements. Materials and structures, 39(8):749-763, 2006.

[6] Bentur A and Mindess S. Fibre reinforced cementitious composites. CRC Press, 2006.

[7] Bournas D, Triantafillou T, Zygouris K, and Stavropoulos F. Textilereinforced mortar versus FRP jacketing in seismic retrofitting of RC columns with continuous or lap-spliced deformed bars. Journal of Composites for Construction, 13(5):360-371, 2009.

[8] Butler M, Mechtcherine V, and Hempel S. Experimental investigations on the durability of fibre-matrix interfaces in textile-reinforced concrete. Cement and Concrete Composites, 31(4):221-231, 2009.

[9] Butler M, Mechtcherine V, and Hempel S. Durability of textile reinforced concrete made with AR glass fibre: effect of the matrix composition. $M a-$ terials and structures, 43(10):1351-1368, 2010.

[10] Carozzi F and Poggi C. Mechanical properties and debonding strength of fabric reinforced cementitious matrix (frcm) systems for masonry strengthening. Composites Part B: Engineering, 70:215-230, 2015.

[11] D'Ambrisi A, Feo L, and Focacci F. Experimental analysis on bond between PBO-FRCM strengthening materials and concrete. Composites Part B: Engineering, 44(1):524-532, 2013.

[12] D'Ambrisi A, Focacci F, and Caporale A. Strengthening of masonryunreinforced concrete railway bridges with PBO-FRCM materials. Composite Structures, 102:193-204, 2013.

[13] De Felice G, De Santis S, Garmendia L, Ghiassi B, Larrinaga P, Lourenço P, Oliveira D, Paolacci F, and Papanicolaou C. Mortar-based systems for externally bonded strengthening of masonry. Materials and structures, 47 (12):2021-2037, 2014. 
[14] Gowripalan N. Effect of curing on durability. Concrete International, 12 (2):47-54, 1990.

[15] Hartig J, Jesse F, Schicktanz K, and Häußler-Combe U. Influence of experimental setups on the apparent uniaxial tensile load-bearing capacity of textile reinforced concrete specimens. Materials and structures, 45(3): 433-446, 2012.

[16] Hempel R, Butler M, Hempel S, and Schorn H. Durability of textile reinforced concrete. Special Publication, 244:87-108, 2007.

[17] ICC-Evaluation Service. Acceptance criteria for masonry and concrete strengthening using fiber-reinforced cementitious matrix (FRCM) composite systems. AC434, 2013. Whittier, CA.

[18] International Code Council. International Building Code. International Code Council: Washington DC, United States, 2012.

[19] Italian National Research Council (CNR). Guide for the design and construction of an externally bonded FRP system for strengthening existing structures. DT200, 2004.

[20] Kajorncheappunngam S, Gupta R, and GangaRao H. Effect of aging environment on degradation of glass-reinforced epoxy. Journal of composites for construction, 6(1):61-69, 2002.

[21] Kootsookos A and Mouritz A. Seawater durability of glass- and carbonpolymer composites. Composites Science and Technology, 64(10):15031511, 2004.

[22] Lanzoni L, Nobili A, and Tarantino A. Performance evaluation of a polypropylene-based draw-wired fibre for concrete structures. Construction and Building Materials, 28(1):798-806, 2012.

[23] Machida A and Uomoto T. Recommendation for design and construction of concrete structures using continuous fiber reinforcing materials. Japan Soc. of Civil Engineers, 1997. 
[24] Mandel J. The statistical analysis of experimental data. Dover Publishing Inc, 2012.

[25] Mobasher B. Mechanics of fiber and textile reinforced cement composites. CRC press, 2011.

[26] Mobasher B, Peled A, and Pahilajani J. Distributed cracking and stiffness degradation in fabric-cement composites. Materials and structures, 39(3): 317-331, 2006.

[27] Nobili A. Durability assessment of impregnated glass fabric reinforced cementitious matrix (GFRCM) composites in the alkaline and saline environments. Construction and Building Materials, 105:465-471, 2016.

[28] Nobili A and Falope F. Impregnated carbon fabric reinforced cementitious matrix composite for rehabilitation of the Finale Emilia hospital roofs: A case study. Journal of composites for construction, 2016. To appear.

[29] Papanicolaou C, Triantafillou T, Papathanasiou M, and Karlos K. Textile reinforced mortar (TRM) versus FRP as strengthening material of URM walls: out-of-plane cyclic loading. Materials and Structures, 41(1):143-157, 2008.

[30] Pellegrino C and D'Antino T. Experimental behaviour of existing precast prestressed reinforced concrete elements strengthened with cementitious composites. Composites Part B: Engineering, 55:31-40, 2013.

[31] RILEM Technical Committee 232-TDT. Test methods and design of textile reinforced concrete. Materials and Structures, 49(12):4923-4927, 2016. ISSN 1871-6873. doi: 10.1617/s11527-016-0839-z.

[32] Stratford T, Pascale G, Manfroni O, and Bonfiglioli B. Shear strengthening masonry panels with sheet glass-fiber reinforced polymer. Journal of Composites for Construction, 8(5):434-443, 2004. 
[33] Triantafillou T. Composites: a new possibility for the shear strengthening of concrete, masonry and wood. Composites Science and Technology, 58 (8):1285-1295, 1998.

[34] Zhutovsky S and Kovler K. Effect of internal curing on durability-related properties of high performance concrete. Cement and concrete research, 42 (1):20-26, 2012. 